\title{
Heart Rate Variability in the Diagnosis of the Health of Participants in the Educational Process
}

\author{
Bashkireva A.V. \\ Department of Biomedical and Psychological Foundations \\ of Physical Education \\ bashkireva32@gmail.com
}

\author{
Bashkireva T.V. \\ Department of General Psychology \\ S.A. Esenin State University \\ Ryazan, Russia \\ bashkirevat@bk.ru
}

\author{
Severin A.E. \\ Department of Normal Physiology \\ University of Peoples' Friendship of Russia \\ Moscow, Russia \\ aesever@mail.ru
}

\begin{abstract}
The article describes the formation of the modern concept of the study of health that arose at the stage of human space exploration. The methodology of heart rate variability, as an indicator of the adaptive reactions of the body, developed in different countries of the world. The study is an important aspect of the research of body reserves in humans, as it allows to obtain information about the tension of the mechanisms of regulation of the body in various conditions of human activity. In connection with the unsatisfactory state of the Russia young population health according to the literature, the work emphasizes the need for practical application of this concept in psychological, pedagogical, psychophysiological prenosological monitoring of the health of not only participants in educational, but also production processes.
\end{abstract}

Keywords - heart rate variability; health; Introduction.

\section{INTRODUCTION}

In the second half of the 20th century, a methodology of heart rate variability (HRV) was developed in prenosological studies. The concept of the cardiovascular system as an indicator of the adaptive reactions of the body in Russia was first set forth in connection with the implementation of human space flight. Contribution to the development of HRV has been made by many scientists from around the world. Analysis of heart rate variability is a modern methodology and technology for the study and assessment of the state of the body's regulatory systems, in particular the functional state of various parts of the autonomic nervous system. In general, HRV is considered as a result of the activation of various regulatory mechanisms that ensure the maintenance of cardiovascular homeostasis. The research is an important aspect of the body reserves study in humans, as it provides information on the tension of regulatory mechanisms in various conditions of human activity. In our opinion, in the study of health problems, the most interesting is the spectral analysis or the analysis of slow hemodynamic fluctuations. Currently, methodological approaches are being actively developed using hardware and software systems that allow monitoring of prenosological health conditions to a complex of stress factors of various nature, unfortunately, which have not been sufficiently introduced into practice.

In recent years, the question of the health problems of students is rising more and more often. According to researchers in large cities, youth health is unsatisfactory [8-9]. According to the Russian consumer supervision, the frequency of functional health disorders in Russian schoolchildren over the past decade has increased 1.5 times, chronic diseases doubled [17]. Medical examinations in educational institutions are carried out without the use of special equipment [1], which does not allow monitoring the functional state of students in modern conditions of socio-psychological pressure on a growing organism; the body of schoolchildren pays a particularly high price of health in preparation for the general state exam (GSE) and the unified state exam (USE). An increase in the retirement age raises the question of mass prenosological studies of the younger generation and timely preventive measures that provide a health-saving education. In the second half of the 20th century, a methodology for heart rate variability (HRV) was developed in research. The concept of the cardiovascular system as an indicator of the body adaptive reactions in Russia was first described in the work of V.V. Parina, R.M. Bayevsky, Yu.N. Volkova, O.G. Gazenko «Cosmic Cardiology» (1967). Researchers believe that the heart is a sensitive indicator of all processes occurring in the body [4-5]. A.N. Fleishman calls the heart «a window through which scientists observe the processes taking place in the body» [3]. The rhythm of its contractions, regulated by the sympathetic and parasympathetic departments of the autonomic nervous system, is very sensitive to any stressful effects. Today, using electronic devices and computing tools, learned to obtain objective data on the state of human health based on an analysis of the heart rhythm. 
N.I. Yabluchansky and A.V. Martynenko believes that heart rate variability (HRV) is a combination of all its properties, due to the non-linearity of sympathetic, parasympathetic and humoral regulation and connections between each other, with subcortical and cortical formations, and reactions to stress types [7]. Contribution to the development of HRV is made by many scientists from around the world [11; 13; 15-17]. In Russia, this methodology was developed thanks to R.M. Baevsky. The development of astronautics required scientists to improve the method of remote study of the astronauts health. And in the 60s, the intensive development of the method of heart rate variability and its use in medical, psychophysiological practice began. In this regard, hardware and software systems are gaining increasing recognition, allowing to get an idea of the functional state of the body in a short time. The number of publications in this area is increasing every year.

Analysis of heart rate variability is a modern methodology and technology for the study and assessment of the state of the body's regulatory systems, in particular the functional state of various parts of the autonomic nervous system. A.I. Grigoriev and R.M. Baevsky explain the mechanism of this methodology, based on the analysis of a dual-circuit model (autonomous and central circuits) of heart rhythm regulation [2]. The autonomous circuit for controlling the rhythm of the heart consists in the fact that the sinus node, under the influence of signals transmitted through the vagus nerve, slows down or accelerates heart contractions to the beat with breathing (sinus respiratory arrhythmia). The sympathetic nerve, which strengthens and accelerates heart contractions, carries commands from the sinus node higher levels of control of the central regulation loop. Under its influence, respiratory arrhythmia is suppressed, and fluctuations with slower periods are intensified (not respiratory fluctuations)

Sinus respiratory arrhythmia was discovered in the last century (Karl F.V. Ludwig, 1847). There is no consensus on the origin of respiratory arrhythmia. Many researchers believe that the effect of breathing on heart rhythm is actually proven. According to W. Sayers (1973), respiration affects the duration of cardiocycles through interpleural pressure and the activity of baroreceptors. M. Klaimes (1963) developed a model of respiratory regulation of heart rate. This model is based on the position of the automatic regulation theory and interprets the relationship between respiration and the magnitude of the "vagal" inhibition of the heart using transfer functions. According to published standards of the European Cardiological Society and the North American Society of Electrophysiology (Heart rate variability, 1996), two groups of methods are distinguished: temporary (Time Domain Methods) and frequency (Frequency Domain Methods). Temporary methods include statistical analysis and geometric methods, and frequency methods include spectral analysis.

\section{RESEARCH METHODOLOGY}

Methods for studying heart rate variability can be divided into three groups: 1) methods for statistical estimation of the numerical array of cardio intervals; 2) methods for assessing the relationship between cardio intervals; 3) methods for revealing the latent periodicity of the dynamic range of cardio intervals. In general, HRV is considered as a result of the activation of various regulatory mechanisms that ensure the maintenance of cardiovascular homeostasis.

\section{RESULTS}

From our point of view, in the study of adaptation problems and adaptive reactions, the most interesting is spectral analysis or analysis of slow hemodynamic oscillations (ICG). The contribution to the study of ICG was made by G. Walter (1964), N.A. Aladzhalova (1979), N.P. Ankylosing spondylitis (1980), M.V. Volkenstein (1981), S. Akselrod (1985), G.R. Ivanitsky, V.I. Krinsky (1982), I. Richards (1988), H. Westerhoff (1992), D. Zhemaitite, especially the work of A.N. Fleischmann (1991-2012). Spectral analysis is one of the methods for studying physiological signals in order to obtain qualitative and quantitative characteristics of oscillatory processes. The energy classifications of the slow hemodynamic waves are developed: 1) norm; 2) energy deficiency state; 3 ) overactive state; 4) hyperactive adaptive reaction; 5) load (post-load) energy shortage; 6) energy fold [3]. According to literature data, the frequency ranges have a specific physiological content: HF is the vago-insular branch of the baroreceptive reflex, LF is the sympathetic branch of the baroreceptive reflex, VLF is the ergotropic function, which was tested and described in Russian studies [10].

Currently, there has been great interest in the nonlinear dynamics of heart rate variability analysis. Contributed to the development of a synergistic approach in physiology and medicine such researchers as J. Murray (1983), R.E. Klinger, J.P. Miller (1987-2009), G. Haken (1991, 2000), I. Prigogine (2000), A.A. Koronovsky A.A., .E. Temples (2002) and others.

A. Rodionov in his work "The clinical significance of the study of heart rate variability" gives a detailed description of HRV histograms [18]. A histogram is a graphical representation of the grouped values of heart intervals, where the temporal values are plotted along the abscissa axis, and their number is plotted along the ordinate axis: 1) a normal histogram, similar in appearance to Gauss curves, is typical for healthy people at rest; 2) asymmetric - indicates a violation of the stationary process, observed in transition states; 3) excessive - is characterized by a very narrow base and a pointed peak, is recorded with severe stress, pathological conditions. There is also a multi-vertex histogram, which is due to the presence of a non-sinus rhythm (atrial fibrillation, extrasystole), as well as multiple artifacts. There are normotonic, sympathicotonic and vagotonic types of histograms, which are used to judge the state of the autonomic nervous system.

The Institute for the Introduction of New Medical Technologies "RAMENA" (Ryazan), together with the Institute of Biomedical Problems of the Russian Academy of Sciences (IMBP RAS, Moscow) developed a specialized hardware-software complex "Varicard", which is recommended by the Russian Ministry of Health as a standard tool for studying cardiac variability rhythm in clinical practice, applied physiology and psychology. The complex provides the implementation of all the main methods of HRV analysis (statistical analysis, variational pulsometry, correlation, 
[2] A.I. Grigoriev, R.M. Baevsky, Health in space. The concept of health and the problem of the norm in space medicine. 1998.

rhythmography, autocorrelation, spectral analysis, etc.) [14]. For a visual display of the results of the assessment of functional states on the analysis data is used (Fig.1).
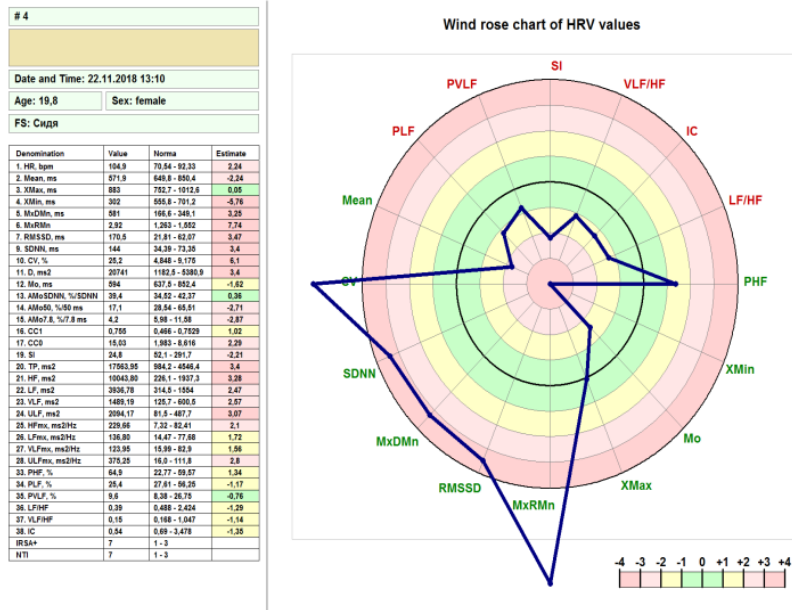

Fig. 1. One of the options for the final document based on the results of a student's study using the Varikard agricultural complex

The color and pattern of functional states with recognizable psychological signs and symbols, allows to form a health image, to regulate, control it. And specialists can develop those wellness technologies that will allow the student and their parents to control the range of individual health standards of the student. Teachers in a timely manner to take a set of recreational activities.

\section{CONCLUSIONS}

Thus, an analysis of literary sources has shown that a methodology for heart rate variability is being actively developed using hardware-software complexes that allow monitoring of prenosological conditions and health of both participants in the educational process and employees of other industrial fields to a complex of stress factors of various nature. Due to the fact that the retirement age in Russia has increased significantly, a systematic mass research of population health of all ages using modern statistical systems is necessary. The results of such studies will allow us to develop those strategies and techniques of health conservation that will be in demand in solving various socio-economic problems.

\section{References}

[1] I.A. Berseneva, E.Yu. Bersenev, I.Yu. Borodina, Age features of the vegetative regulation of heart rhythm in schoolchildren and their importance for improving the pedagogical process. Proceedings of the VIII International Symposium "Ecological and physiological problems of adaptation". 1998 , pp. 50-51.
[3] A.N. Fleishman, Slow hemodynamic oscillations. Theory, practical application in clinical medicine and prevention. Novosibirsk, Science. Sib. Enterprise RAS. 1999, pp. 264.

[4] N.A. Agadzhanyan, R.M. Baevsky, A.P. Berseneva, The study of health and problems of adaptation (theory and practice of valeological research). - M., Stavropol. 2000, pp. 204.

[5] R.M. Baevsky, G.P. Ivanov, L.V. Chireykin, A.P. Gavrilushkni, P. Dovgalevsky, Yu.A. Yakushkin, T.F. Mironova, D.A. Prilutsky, Yu.N. Semenov, V.F. Fedorov, A.N. Fleshman, MM. Medvedev, Analysis of heart rate variability using different cardiographic systems. Bulletin of arrhythmology. 2001, 24, pp. 65-87.

[6] A.N. Fleishman, Heart rate variability and slow hemodynamic fluctuations: non-linear phenomena in clinical practice. Novosibirsk: Publishing House of the Siberian Branch of the Russian Academy of Sciences. 2009, pp. 194.

[7] N.I. Yabluchansky, A.V. Martynenko, Heart rate variability to help the practitioner. For real doctors. Kharkiv. 2010, pp. 131.

[8] T.N. Semenkova, The state of health of the studying youth. Bulletin of KemSU. 2011, 2(46), pp. 90-97.

[9] E.V. Gallyamova, R.N. Kildebekova, L.R. Mingazova, The state of health of young people in a large industrial city. Modern medicine: current issues: Coll. Art. on mater. XII international scientific-practical conf. - Novosibirsk: SibAK. 2012.

[10] T.V. Bashkireva, Physiological basis of the features of adaptive responses in athletes paratroopers in the extreme conditions of professional activity. Dissertation for the degree of Doctor of Biological Sciences: 03.03.01/ SEIHPE "Peoples' Friendship University of Russia". 2013. URL: https://elibrary.ru/author_items.asp

[11] I. María Irurzun, Elías Mola Heart Rate Variability: A View from Chaos Theory. LAP LAMBERT, Academic Publishing. 2015-02-24, pp. 60.

[12] E.A. Valueva, A.A. Grigoriev, D.V. Ushakov, Dyssynchrony of cognitive development in intellectually gifted children: a structuraldynamic approach. Psychological journal. 2015, vol. 36, 5, pp. 55-63.

[13] V. Vesterinen, K. Häkkinen, T. Laine, E. Hynynen, J. Mikkola, A. Nummela, Predictors of individual adaptation to high-volume or highintensity endurance training in recreational endurance runners. Scand J Med Sci Sports. 2016, 6(8), pp. 885-93.

[14] Complex for the analysis of heart rate variability. Varicard JIMNZ. 941111.001 PS. 2018.

[15] Adrian Low, Rollin McCraty, McKiernan. Effects of Workplace Stress on Employee's Heart Rate Variability. Scholar's Press. 2018-0821 , pp. 180 .

[16] Abdul Qahar Sarwari. Communication Competence and Heart Rate Variability. Scholars' Press, 2018-03-21, pp. 236.

[17] School. Dangerous for health. URL: https://www.m24.ru/articles/obshchestvo.

[18] Alexsandr S. Kuznetsov. Russian Professor's meeting. Russian Journal of Physical Education and Sport. 2019, 14(1), pp. 17-22. DOI: DOI 10.14526/2070-4798-2019-14-1-18-24

[19] A. Rodionov, The clinical significance of the study of heart rate variability. URL: www.nedug.ru 